Orbis Tertius, vol. XXVI, n 33, e197, mayo-octubre 2021. ISSN 1851-7811

Universidad Nacional de La Plata

Facultad de Humanidades y Ciencias de la Educación

Centro de Estudios de Teoría y Crítica Literaria

\title{
El despegue de la modernidad cinética - De los pioneros hasta Jorge Luis Borges y Juan José Saer
}

\author{
From the takeoff of kinetic modernity to air mobility: pioneers, Latin American \\ aesthetic avant-garde, Borges and Saer
}

Guillermo Giucci

giucci@uol.com.br

Universidad del Estado de Rio de Janeiro, Brasil

Cita sugerida: Giucci, G. (2021). El despegue de la modernidad cinética - De los pioneros hasta Jorge Luis Borges y Juan José Saer. Orbis Tertius, 26(33), e197. https://doi.org/10.24215/18517811e197
Resumen: El artículo examina momentos clave de la historia cultural de la aviación. Partiendo de la noción de "modernidad cinética”, en su vertiente aérea, considera figuras representativas de los éxitos y fracasos de la aeronáutica. El afamado Charles Lindbergh adquiere relieve como símbolo del pasaje de la aviación pionera a la comercial. Se concede especial atención a escritores de vanguardia latinoamericanos, con frecuencia desprovistos de la experiencia directa del vuelo, que acompañaron la evolución de la aviación como una aventura estética. Como contraste a la etapa "heroica", el artículo hace además referencias a la banalización de la aviación en Jorge Luis Borges y Juan José Saer y concluye con el concepto de "aeromovilidad" como expresión de la movilidad planetaria.

Palabras clave: Modernidad cinética, Aeromovilidad, Charles Lindbergh, Jorge Luis Borges, Juan José Saer.

Abstract: The article examines key moments in the cultural history of aviation. Starting from the notion of "kinetic modernity", in its aerial aspect, it considers representative figures of the successes and failures of aeronautics. The famous Charles Lindbergh is highlighted as a symbol of the transition from pioneering to commercial aviation. Special attention is given to Latin American avant-garde writers, often devoid of the direct experience of flight, who accompanied the evolution of aviation as an aesthetic adventure. As a contrast to the "heroic" stage, the article also makes references to the trivialization of aviation in Jorge Luis Borges and Juan José Saer and concludes with the concept of "aeromobility" as an expression of planetary mobility.

Keywords: Kinetic modernity, Aeromobility, Charles Lindbergh, Jorge Luis Borges, Juan José Saer.

\section{INTRODUCCIÓN}

In the past human life was lived in a bullock cart; in the future it will be lived in an aeroplane; and the change of speed amounts to a difference in quality.

Alfred North Whitehead, Science and the Modern World, 1925 
Cuando el 23 de octubre de 1906, en el Campo de Bagatelle, París, Alberto Santos Dumont conquistó la Taza Archdeacon y los 3.000 francos ofrecidos al piloto que, en su máquina y por sus propios medios, consiguiese elevarse del suelo y volar por lo menos 25 metros, quedaba claro que la emoción estaba en el aire. La navegación aérea, los premios y la fama inmediata del aviador indican el contundente despegue oficial de la modernidad cinética.

\section{PLACER Y BENEFICIO: DE LA MANUTENCIÓN DEL EQUILIBRIO AL DOMINIO DEL AIRE}

La máquina de volar más pesada que el aire constituye el primer gran invento del siglo XX. Llega después del tren, la fotografía, el telégrafo, el teléfono, el cine, la luz eléctrica, la bicicleta, el tranvía eléctrico, el automóvil -todos inventos del siglo XIX, especialmente de sus últimas décadas. Y, sin embargo, ninguna de las invenciones mencionadas implicaba una aspiración tan antigua como el anhelo de volar. El polémico psicoanalista vienés Sigmund Freud, en La interpretación de los sueños, libro publicado en 1899 pero posdatado 1900 para que apareciese como del nuevo siglo, se refiere a los "sueños de vuelo" como una modalidad de los sueños típicos y los enlaza con el deseo oculto de las actividades sexuales (1989, p. 279).

En 1900, mientras en la Exposición Universal de París se presentaba la grabadora magnética del inventor danés Valdemar Poulsen, entre muchos otros artefactos de la ciencia moderna, la promesa de la aviación se tornaba una posibilidad real. En septiembre de ese año, Wilbur Wright le envió una carta a su padre comentando su deseo de iniciar experimentos con una máquina voladora (Wohl, 1994, p. 10). Si bien en principio se investiga más por placer que por ganancia, el proyecto de volar en una máquina más pesada que el aire aparece asociado con la fama y la fortuna. Dice Wilbur que cree que el vuelo es posible y que hay una pequeña probabilidad de obtener, justamente, fama y fortuna de ello. Su confianza es evidente, pues tiene la certeza de que podrá alcanzar un resultado muy superior a los trabajadores previos en esa área, aunque el éxito completo no se logre de inmediato.

Los hermanos Wilbur y Orville Wright viven en Dayton, Ohio, Estados Unidos. Poseen un conocimiento práctico, derivado principalmente de su trabajo con bicicletas y automóviles. Orville era "el inventor", tímido, y no le gustaba hablar en público; en cambio, a Wilbur le hubiera gustado ser profesor. No fuman, beben o apuestan. Nunca se casan. Son detallistas, prudentes, rigorosos y puritanos. Son burócratas cumpliendo de modo implacable su tarea. Se proyectan como inventores, no como mecánicos, deportistas o acróbatas. Como lo habían prometido a su padre -el severo obispo Milton Wright-, nunca vuelan juntos (solo volaron juntos una única vez, precisamente en una demostración para el padre). Su vínculo con la máquina voladora es, en la medida de lo posible, de control. Intentan constantemente disminuir el riesgo al mínimo. Nada heroico. De modo silencioso y eficiente, avanzan en los fundamentos del balance y el control. Para ser práctica, toda máquina de movimiento debe ser controlable. Nadie contribuyó tanto al problema del equilibrio, en esta fase de la consagración del movimiento aéreo, como los hermanos Wilbur y Orville Wright.

El biógrafo Tom Crouch (1989) se pregunta cómo estos dos hombres, que a sus amigos y vecinos parecían tan comunes, lograron tanto en una vida. Los W right no buscaban publicidad ni premios en dinero. Protegían su trabajo, que se desarrollaba prácticamente en secreto, y aspiraban a vender el aeroplano por ellos inventado a varios gobiernos. Durante la primera década del siglo XX, mantuvieron una ventaja considerable sobre sus rivales. Ello se debió a que se abocaron a resolver los fundamentos del control aerodinámico. El problema del equilibrio era el obstáculo crucial del vuelo según los hermanos Wright, y la capacidad para controlar el aeroplano los diferenció en esta etapa de otros aviadores.

Los Wright contaron con la ayuda del máximo especialista en estudios aeronáuticos de la época: Octave Chanute. Este ingeniero civil nacido en 1832 en Francia, que desde los seis años vivía en Estados Unidos, se tornó un apoyo invalorable. Había organizado en 1893 la conferencia internacional sobre navegación aérea, 
con la participación de cien delegados de distintas partes del mundo y celebrada ante un público numeroso en la Exposición Universal de Chicago. Por otra parte, en 1894 había publicado Progress in Flying Machines, considerado uno de los libros más importantes en la historia de la aviación. Fue un libro que proporcionó a los entusiastas de la aviación una base sólida de las invenciones y experimentos relacionados con el problema del vuelo mecánico.

A Chanute lo guiaba una motivación pragmática. Estaba convencido de que las dificultades del vuelo artificial eran considerables, pero no insuperables. Estamos ante un libro extraño -en realidad, una serie de artículos publicados entre 1891 y 1893 - que combina la objetividad, el pragmatismo, la historia de los experimentos, fórmulas matemáticas y predicciones. Se examinan variados tipos de vuelo y de máquinas voladoras (diferentes de globos), incluyendo la leyenda de Simón el mago y los dibujos de Leonardo da Vinci. Siempre se esfuerza Chanute por mostrar los aspectos positivos y negativos de tales experimentos, a fin de que el piloto no se vea obligado a repetir los errores del pasado. Se trata de una mina de información práctica, que los hermanos Wright leyeron con sumo cuidado y del cual extrajeron importantes lecciones.

La mayor parte del libro está dedicada a los aeroplanos y a las soluciones posibles ante las dificultades del vuelo. Chanute (1894) enumera diversos problemas con planeadores que tendrían que ser resueltos para que el sueño humano de volar se torne una realidad: la resistencia y el poder de soporte del aire, las características del motor, los instrumentos para obtener propulsión, la forma y tipo de los aparatos, su material y textura, que pueda ser dirigido hacia cualquier dirección, el arranque bajo todas las condiciones, el aterrizaje seguro en cualquier lugar.

De los problemas mencionados, ninguno es tan relevante como la manutención del equilibrio. Chanute insiste una y otra vez sobre el problema de la estabilidad, pues considera que básicamente los fracasos en la experimentación práctica resultaron de una falta de equilibrio. Una vez resuelto el trastorno del equilibrio, sostiene Chanute, el hombre podrá tener esperanza en navegar por el aire. Como corresponde al científico fanático de la modernidad cinética, es necesario un proceso de evolución que arranca de modelos imperfectos para ascender a los más perfectos. La máquina de volar tendrá que ser modificada, reconstruida y reconfigurada muchas veces para que se obtenga una forma práctica y segura. Y el inventor tendrá que construir los primeros modelos con dinero propio, antes de poder comercializar el producto.

La correspondencia entre los hermanos Wright y Octave Chanute comenzó en 1900. Hasta la muerte de este último, en 1910, fueron 435 cartas, además de varios encuentros personales. Chanute fue una referencia para que los hermanos Wright expusieran sus ideas y refinasen sus procedimientos. Sin embargo, mientras que el ingeniero partía del principio de compartir información y del esfuerzo cooperativo, los Wright trabajaban solos y preferían esconder la información, discrepancia que los llevaría a desentendimientos posteriores. Mientras tanto, los Wright se preocupaban por encontrar un lugar adecuado para llevar a cabo sus experimentos. Escribieron al U.S. Weather Bureau en Washington pidiendo información sobre las condiciones climáticas en varias partes del país. Descubrieron así que Kitty Hawk, en Carolina del Norte, lugar del que nunca habían oído hablar antes, combinaba un alto porcentaje de viento con un número razonable de días claros en el otoño.

Ya en marzo de 1903 los hermanos Wright pretenden patentar una máquina de volar. La patente solicitada era tan amplia y vaga que prácticamente establecía un monopolio sobre cualquier máquina de volar. Fue rechazada por la Oficina de Patentes. En todo caso, el primer vuelo de la historia con una máquina más pesada que el aire se llevó a cabo en las colinas de Kill Devil, en Carolina del Norte, a las 10:35 de la mañana, el 17 de diciembre de 1903, utilizando un motor a gasolina, aunque dependiendo de una catapulta de lanzamiento.

El vuelo artificial era potencialmente un gran negocio. Para obtener ganancias, se hacía necesario producir un aeroplano de utilidad práctica, una máquina de volar que interesase a los gobiernos de Estados Unidos, Francia, Inglaterra, Alemania. Los Wright querían vender su invención, y poco les importaban los motivos militares de los compradores. La modernidad cinética no podía depender solo del espectáculo deportivo. La dimensión empresarial de la investigación aérea es un elemento clave, al punto de que la máquina voladora de 
los hermanos Wright será sucesivamente ofrecida a diferentes gobiernos para fines militares. Cuando Wilbur pilota su máquina en París, en 1908, corroborando la ventaja de los norteamericanos en relación con los demás países y aviadores, llegan la fama, los pedidos y la fortuna. Antes escépticos, los gobiernos solicitan aeroplanos Wright y los hermanos entregan su primer aeroplano al Departamento de Guerra de los Estados Unidos por 25 mil dólares en 1909, hecho que posteriormente será interpretado como la temprana formación del complejo militar-industrial norteamericano.

A tal velocidad progresaba la modernidad cinética que pocos años después, cuando en 1912 Wilbur Wright murió a los 45 años de una fiebre tifoidea, la Compañía Wright estaba quedando tecnológicamente rezagada en relación con sus rivales europeos. Orville vendió la Compañía en 1915: otros inversores estaban ansiosos por proseguir el negocio del vuelo artificial. La Primera Guerra Mundial consolidó la importancia de la aviación. Aunque todavía estamos a medio camino entre el espectáculo y la utilidad, ya en 1921 el general italiano Giulio Douhet discurre sobre el empleo del avión en el conflicto bélico. En su texto, sintomáticamente titulado El dominio del aire, Douhet (1987) anuncia que hasta entonces el aeroplano había sido un auxiliar magnífico de la artillería, pero que en el futuro próximo asumiría una posición de centralidad.

\section{Celebridad Celestial: la Forja de Un Mito}

A inicios del siglo XX era impensable que un joven aviador llegara a ser la persona más célebre del planeta. Charles Lindbergh no puede ser destronado como máximo representante aéreo de la modernidad cinética, merced a su histórico vuelo transatlántico de 1927 y a su actividad incansable en beneficio de la aviación comercial. Aquí comienzan los problemas, pues tampoco es posible pensar a este individuo fuera de una compleja organización social, económica y tecnológica que le sirve de apoyo. El "mito Lindbergh" es un testimonio del individualismo, asimismo del capitalismo, del perfeccionamiento de la ingeniería aeronáutica, del avance de los sistemas de comunicación, de la cooperación entre la ciencia y la tecnología, y del prestigio de la incipiente sociedad del espectáculo.

Con Lindbergh la modernidad cinética alcanza un momento de gloria. Parece que el movimiento no tiene límites: su vuelo Nueva York-París da lugar a una euforia popular transnacional. Lindbergh es elogiado por los periódicos del mundo, ovacionado por multitudes, recibido por presidentes, cortejado por políticos, directores de cine y millonarios. Desde la noche en que aterrizó en París, el 21 de mayo de 1927, se encontró lanzado hacia una odisea para la cual estaba mal preparado: ser una estrella mediática.

"[Lindbergh] se convirtió en la persona viviente más celebrada en el mundo", escribe el biógrafo A. Scott Berg; las personas se comportaban como si hubiese caminado sobre el agua, no volado sobre ella (Scott Berg, 1998, p. 6, la traducción es nuestra). Osado y obstinado, nacido en Detroit, Michigan, el 4 de febrero de 1902, Lindbergh era un enamorado de la aviación y un apasionado de sus posibilidades. Se inició en el "Barnstorming", término que indica los vuelos que efectúa el aviador de una ciudad a otra, tomando en cada una a los pasajeros que se arriesgan a volar (en la época se solía cobrar cinco dólares por un vuelo de una duración de cinco a diez minutos). Su ambición era poseer una máquina de volar. Adquirió un modelo Jenny usado, con un motor nuevo Curtiss OX-5 y un equipo completo, por 500 dólares: para siempre permanecerá grabado el recuerdo del primer vuelo que realiza en su aeroplano, solitario, a centenares de metros por encima de la tierra.

Hay que aprovechar todas las horas del día, incluso la noche. Lindbergh comienza a volar de noche, pese a las precarias condiciones de iluminación en los campos de aterrizaje. En el Servicio Aéreo del Ejército encuentra este cadete aviador la oportunidad de pilotar máquinas poderosas y de ensayar ejercicios acrobáticos: rizos, descensos en espiral, toneles o medios toneles, giros Immelman, ochos, vuelos invertidos y vuelos en formación. No desconoce la probabilidad de la mors repentina, pero evita riesgos innecesarios.

Como funcionario en el Departamento de Correos Aéreos, que inauguraba sus servicios postales en parte desplazando los demás medios de transporte, Lindbergh concibió el vuelo Nueva York-París. Recordemos 
que los premios eran un poderoso incentivo para los pioneros. El emigrado francés a los Estados Unidos, Raymond Orteig, que deseaba acentuar los aspectos positivos de la relación entre ambos países, había ofrecido un premio de 25.000 dólares para el primer aviador del vuelo transatlántico Nueva York-París (o el inverso). Lindbergh comprendió que había personas y entidades lo suficientemente interesadas en la aviación como para contribuir a la realización del arriesgado proyecto.

No es necesario entrar en detalles respecto a la serie de problemas técnicos y humanos enfrentados hasta que Lindbergh logró despegar de Nueva York en el Spirit of St. Louis, la mañana del 20 de mayo de 1927. En cambio, se impone mencionar que se trató de un esfuerzo colectivo, de un plan cuidadoso y de una demostración de destreza tecnológica norteamericana. El monoplano, de un solo motor, fue adquiriendo forma durante su construcción por parte de la Ryan Aircraft Corporation de San Diego y supervisada metódicamente por el propio Lindbergh, desde unos cuantos metros de tubos de acero hasta conformar un eficiente aeroplano capaz de transportar un piloto dispuesto a enfrentar un desafío mortal. Varios pilotos experimentados, europeos y norteamericanos, intentaron vencer en esa contienda. En cambio, sería un joven aviador desconocido -audaz, bonito, alto, soltero, cordial- el que a los veinticinco años encarnara el símbolo romántico del triunfo de la modernidad cinética.

El historiador Robert Wohl (2005) proporciona valiosa información sobre el "fenómeno Lindbergh". Demuestra que, contrariamente a la opinión corriente, Lindbergh no fue el primer aviador en cruzar el Atlántico por aire. Ya en 1919, Albert Read y su tripulación de cinco ayudantes aterrizaron el hidroavión NC 4 en Lisboa, tras once días de vuelo y una parada en las islas Azores. Poco después John Alcock y Arthur Brown realizaron el primer vuelo sin escalas a través del Atlántico Norte, desde Isla de Terranova a Irlanda, en dieciséis horas y veintiocho minutos. Ninguno de estos vuelos, así como otros pocos, aclara Wohl, formaron parte de la carrera transatlántica.

Cuando en 1919 se había instituido el Premio Orteig de 25.000 dólares al que lograra atravesar en un vuelo sin escalas el trecho París-Nueva York o el inverso, no existían motores lo suficientemente potentes y confiables para llevar a cabo tal empresa. Las condiciones eran distintas cuando tan solo cinco años después, en 1924, Orteig renovó la oferta del premio por la próxima media década. De ambos lados del Atlántico, de Francia y de Estados Unidos, surgieron pilotos dispuestos a ganar el premio y lucrar con la fama. Sin embargo, debido al sistema de vientos, que tendían a soplar hacia Europa, resultaba conveniente el viaje del oeste al este. Por tal motivo, el piloto francés René Fonck viajó a Nueva York y desde allí intentó el vuelo transatlántico, que fracasó en la partida, cuando en septiembre de 1926 el pesado S-35 sufrió un accidente que costó la vida a dos de los cuatro tripulantes. También acabó en tragedia la tentativa de Noel Davis y su compañero Stanton Wooster, que fallecieron durante una prueba de vuelo. El más comentado de los fracasos fue el de los franceses François Coli y Charles Nungesser, pilotos experimentados que se aventuraron desde París en el Oiseau Blanc el 7 de mayo de 1927, y desaparecieron al dejar la costa de Francia. Nunca más se supo de los afamados aviadores. En ese contexto de fracasos y desgracias, informa Wohl (2005, p. 9-19), se inscribe la exitosa travesía aérea transatlántica de Charles Lindbergh.

Lindbergh rápidamente publicó un libro, titulado $W e$ (1927), narrando su viaje. Es una autobiografía "mecánica", desprovista de referencias a su vida íntima. Lo escribió en tres semanas y ni siquiera tuvo tiempo de releer partes del manuscrito. Incluso encargó a Fitzhugh Green que redactase un apéndice de la recepción en Europa y Estados Unidos. El título fue inventado por su editor y los lectores lo entendieron como una referencia a la fusión del piloto y su máquina. De hecho, en castellano se editó el mismo año con el título $M i$ aeroplano y yo, con prólogo del comandante Ramón Franco, hermano menor del futuro dictador Francisco Franco y que en 1926 había realizado un arduo y célebre vuelo en el hidroavión Plus Ultra, de Palos de la Frontera (España) hasta Buenos Aires (Argentina), con escalas en Brasil y Uruguay.

Entre el relato de la experiencia y la lectura por parte del consumidor, suele haber una desemejanza. Pese a que Lindbergh se diferencia del aeroplano durante la narración, el plural "nosotros" aparecía para el lector como la imagen del sujeto fusionado con el objeto, al modo del centauro. Además, la supuesta autosuficiencia 
e independencia de inversores, medios de comunicación e ingeniería mecánica, le confería al piloto el aura del venturoso sujeto libre. Contra todos los vaticinios, tras treinta y tres horas y media de travesía aérea, el Lone Eagle había arribado triunfante a su destino; había llegado "Lucky Lindy", el nuevo Cristo en su crucifijo de metal. De acuerdo con Eksteins, Lindbergh parecía satisfacer simultáneamente dos mundos, uno en la agonía del declive - tradicional, familiar, honrado, que aprovechaba la tecnología para domeñar la naturaleza y reconocía la realización individual basada en el esfuerzo- y otro en proceso de nacimiento -admiraba la acción en el contexto bélico, afirmaba la vida en medio de la muerte y veneraba el futuro (1990, p. 320).

En este péndulo que oscila entre la tradición y la modernidad, en este debate generado por el prototipo contradictorio del pionerismo individualista tecnológico, que abre una nueva frontera que amenaza el espíritu humano, la aeronavegación expresa su apogeo y la modernidad cinética se regocija. Fitzhugh Green escribió el apéndice al libro $W e$ de Lindbergh y relató la recepción del aviador en Europa y Estados Unidos. Informa que cuando el aviador retornó a Estados Unidos, tras festejos y despedidas multitudinarios en Francia, Bélgica e Inglaterra, tuvo la recepción más grandiosa que se ha tributado a ningún hombre del planeta. Y señala que la victoria del individuo representa el triunfo de la especie humana sobre los elementos contra los cuales la debilidad del hombre había luchado durante siglos. Concluye Green que "jamás, en la historia del mundo, se ha visto un entusiasmo tan delirante por un hombre como el que se demostró hacia este héroe norteamericano que realizó tan estupenda hazaña" (citado en Lindbergh, 1927, p. 202, la traducción es nuestra).

$W e$ fue un libro extremamente popular. En un mes, se habían vendido casi 200.000 ejemplares, y para Navidad el editor Putnam preparó una edición especial para niños. Un año después de editado, alcanzó la astronómica cifra de 635.000 copias vendidas, siendo traducido de inmediato a varias lenguas. Parte del éxito, afirma el biógrafo Scott Berg (1998), se debió a la oportuna combinación del libro con el Tour Guggenheim, que contribuyó para crear una tormenta de publicidad que resultó en una obsesión por Lindbergh. En efecto, éste partió en el Spirit of St. Louis de Long Island a mediados de 1927, y por los próximos tres meses recorrió gran parte de Estados Unidos, siendo aclamado en cada ciudad como un ejemplar de "historia viviente" y como héroe nacional.

El profeta de la era aérea estimuló la publicación de decenas de biografías, en su mayoría de carácter hagiográfico, lo que a su vez reforzó el prestigio de la aviación comercial. Recibió tantas cartas y telegramas -se calcula que más de 2 millones- que respondió por medio de la prensa que era imposible leer y contestar esa montaña de comunicaciones. Apareció en poemas, revistas, libros; en periódicos, fotografías, películas, composiciones musicales, medallas, trofeos, monedas, sellos. Muchos niños recién nacidos recibieron su nombre. Tristemente, esa misma fama motivó en 1932 el secuestro, pedido de rescate y asesinato de su hijo de veinte meses. Como personaje público, empañó su trayectoria con el sello de la infamia cuando en 1938 se declaró simpatizante del Tercer Reich, partidario de Adolf Hitler, de su política antisemita y de la eugenesia, recibiendo incluso en una cena una medalla de condecoración de manos de Hermann Göring, el comandante en jefe de la Luftwaffe, en nombre del propio Führer. Estigmatizado tras la derrota de la Alemania nazi -en parte a causa de su resistencia inicial a la participación de Estados Unidos en el conflicto bélico-, siempre admirado como una figura legendaria por el gran público, decepcionado con el rumbo de la mecanización y la agresión a la naturaleza, Lindbergh se retiró a Hawái, donde falleció en 1974.

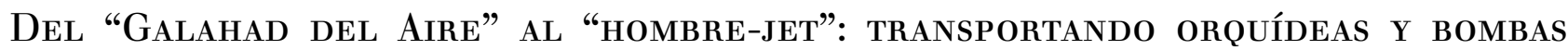 ATÓMICAS}

Sir Galahad es un caballero ficticio de la Mesa Redonda del rey Arturo que alcanzó el Grial en las leyendas artúricas. Charles Lindbergh recibió el apodó "Galahad del Aire” y tuvo sus sucesores. Uno fue Hubert Fauntleroy Julian, nacido en Trinidad en 1897, emigrado en 1921 al Harlem y primer piloto negro en obtener una licencia de vuelo. Era conocido como "Black Eagle” y el "Lindbergh of His Race”, apodos elogiosos en 
la época que en la actualidad suenan despectivos. Otro ejemplo es Amelia Earhart. Casada con el editor George Putnam, que publicó $W e$, Amelia Earhart debía ser la "Lindy" femenina y fue promovida como "Lady Lindbergh”. En 1932 atravesó el Atlántico y cinco años después falleció cuando intentaba el primer viaje aéreo alrededor del mundo sobre la línea ecuatorial.

El ejemplo de Earhart es llamativo, pues aprovechó el "parecido" con Lindbergh para reforzar su fama. Hoy el aprovechamiento de esa supuesta semejanza de Amelia con Charles para fines de renombre resulta una estrategia sospechosa, si no directamente desacertada, en la interpretación del género. En su biografía de Amelia Earhart, Lovell sugiere que Putnam se esforzó por construir el mito "Lady Lindy" y que varios periódicos fueron críticos al respecto. Tenía 38 años cuando el 2 de julio en 1937 desapareció en el Océano Pacífico (Lovell, 1989, p. 111). El mismo año se publicó póstumamente Last Flight, con las cartas e informaciones enviadas a su esposo durante las paradas. Recordemos que Amelia Earhart había impulsado de modo entusiasta la aviación entre las mujeres; también vale la pena recalcar que en Last Flight, Earhart discute el tema del género en relación con la máquina de volar, argumentando que en ocasiones las mujeres no debían únicamente repetir las hazañas masculinas, sino superarlas, "de ese modo estableciéndose a sí mismas como personas, y quizás estimulando a otras mujeres hacia una mayor independencia de pensamiento y acción" (1988, p. 30, la traducción es nuestra).

Muchos años después de su libro We, Charles Lindbergh publicó The Spirit of St. Louis (1953), una narración sumamente detallada de su célebre viaje transatlántico. Identificó el avión con una alfombra mágica, como si procediera directamente de los cuentos de Las mily una noches, para transportarlo a cualquier lugar del mundo, y desmintió rumores falsos sobre su vida y vuelos. Demoró catorce años escribiendo el libro, y continuó refiriéndose al Spirit of St. Louis como un avión maravilloso. Pero a inicios de los años cincuenta las condiciones históricas habían cambiado de manera radical, y consecuentemente emergen las contradicciones. El 6 de agosto de 1945, desde el avión bombardero B-29 Enola Gay, se había lanzado una bomba atómica apodada Little Boy sobre Hiroshima, arrasando casi por completo la ciudad japonesa; tres días después, el 9 de agosto, se lanzó desde el avión bombardero B-29 Bockscar la bomba atómica Fat Man sobre la ciudad japonesa de Nagasaki. Se calcula que las bombas nucleares mataron por lo menos ciento veinte mil personas de modo instantáneo (ese número se duplica en años posteriores debido a las dosis de radiación que provocaron cáncer y defectos genéticos) y persiste la discusión sobre la necesidad de su uso entre detractores y defensores. Más allá de la rendición de Japón, los bombarderos con sus bombas nucleares arrojadas desde el cielo se habían convertido en una amenaza capaz de destruir el planeta.

Una consecuencia de tales cambios es la ambivalencia de Lindbergh sobre los efectos del progreso tecnológico. Cree que algún día los aviones podrán reemplazar al automóvil, así como este reemplazó a los caballos. Sin embargo, no le agrada la idea de millones de aviones volando por el aire. Por supuesto, desea el desarrollo de la aviación en la industria y el comercio, al tiempo que adora la soledad del cielo. El éxito de la aviación a la vez significaba para este precursor legendario el fin de un estilo de vida tradicional que amaba.

La modernidad cinética invade el cielo, así como había conquistado la tierra con sus trenes, tranvías eléctricos, motocicletas, automóviles, ómnibus y camiones. Es el anuncio del triunfo del "fordismo" del aire. "El futuro de la aviación" - había escrito Henry Ford- "no consiste en vender emociones al público sino en transportar personas y cargas de un lugar a otro en el servicio de la industria" (1926, p. 209, la traducción es nuestra). Y Lindbergh, el pionero romántico que trabajó como consultor para las fábricas Ford, se debate inútilmente ante la masificación del transporte aéreo. No solo se transitó de la etapa de la invención, cuando los apasionados hablaban de "la conquista del aire", a la utilidad, sino que un inédito ciclo se iniciaba con el sueño de los vuelos supersónicos y los cohetes espaciales. En ese nuevo mundo casi sobrehumano, anota un preocupado Lindbergh, se encuentran imperfecciones alarmantes. La aviación destruye la civilización que la creó y amenaza el espíritu de la humanidad, pues los aviones llevan desde orquídeas a bombas atómicas.

Cuando, al final de su existencia, Lindbergh escribió Autobiography of Values, se lo comenzó a asociar con la frase "Si yo tuviera que elegir, tendría más bien pájaros que aeroplanos". En el transcurso de una vida, no 
solo había experimentado los cambios históricos del siglo XX, sino que había participado activamente en muchos de los debates. Fue un propulsor enérgico de la aviación comercial y de la investigación espacial, simpatizó abiertamente con la Alemania nazi y trabajó como consultor para Henry Ford (titánico industrial que compartía el ideal antisemita, expuesto en su libro de 1920, The International Jew: The World's Foremost Problem, libro que seguramente influyó en la formación de la ideología nacionalsocialista; que donó dinero para el partido de Hitler; que fue condecorado en 1938 por los nazis con la más alta medalla concedida a un extranjero). Además, Lindbergh invirtió tiempo y dinero en la fabricación de un corazón artificial, defendió la política de "Primero América" y se convirtió en un diligente ecologista, con toques de misticismo. El último Lindbergh está desencantado con la homogeneización del planeta y con la "mortífera estandarización traída por la comunicación veloz" (Lindbergh, 1992, p. 41). Se siente responsable por los efectos perversos del progreso de la aviación y considera, en la línea de Henry Thoreau, que la verdadera libertad radica en la selvatiquez, no en la civilización. En particular, el desagrado manifestado por el desarrollo del transporte aéreo -aquello que una vez le había parecido la ruta maravillosa para incrementar la libertad humana y aproximar a las personas en la comprensión y la paz- es un indicador de su ingenuidad. Tardó para percibir que aproximar de manera física a las personas no significa necesariamente ni mayor comprensión ni paz mundial.

Con Lindbergh concluye el mito dorado del aviador. Sin duda, acuden otros que continúan representando la imagen de la aventura aérea romántica, como Antoine de Saint-Exupéry y Howard Hughes. Pero el piloto-héroe, aquel que combina velocidad, aventura y humanidad, tiene los días contados y en breve será reemplazado por el hombre-jet, piloto de los aviones a reacción y soldado del complejo militar-industrial. Roland Barthes resume las características del hombre-jet: está más próximo del robot que del héroe, pierde parte de su humanismo, la ropa lo torna irreconocible, es un héroe cosificado. Lo que espanta en la mitología del hombre-jet, reflexiona el semiólogo francés, es la eliminación de la velocidad. Se torna necesario aceptar la paradoja que demasiada velocidad se vuelve reposo. Barthes lo sintetizó del modo siguiente:

\footnotetext{
El piloto-héroe se singulariza por toda una mitología de la velocidad sensible, del espacio devorado, del movimiento embriagador; el jet-man se definirá por una cenestesia del in-situ (“a 2000 por hora, altura constante, ninguna impresión de velocidad”), como si la extravagancia de su vocación consistiera precisamente en sobrepasar el movimiento, en ir más rápido que la velocidad. La mitología abandona las imágenes del roce exterior y aborda una pura cenestesia: el movimiento ya no es percepción óptica de los puntos y de las superficies; se ha convertido en una especie de confusión vertical, hecha de contradicciones, oscurecimientos, terrores y desvanecimientos; ya no es deslizamiento, sino estrago interior, turbación monstruosa, crisis inmóvil de la conciencia corporal (Barthes, 1999, pp. 52-53).
}

El avatar posterior del hombre-jet es el astronauta, como parte del proyecto de dominio del espacio cósmico. Dado que Barthes publicó Mythologies en 1957 (los textos que componen el libro se escribieron entre 1954 y 1956), en "L'homme jet" no se hace referencia al astronauta. Pero podemos extender la misma lógica de Barthes a la figura del cosmonauta. Aunque éste será inicialmente percibido como un piloto-héroe, gracias a la apertura de una nueva frontera, una vez superada esa fase de pionerismo, desaparece en su costosa cápsula espacial y en la inmensidad del universo.

\section{“Traer alas, SER menos mueble”: los “PAisajes aViónicos” De América Latina}

Como portavoz de la modernidad cinética, Charles Lindbergh se esforzó para divulgar el evangelio de la aviación comercial en América Latina. En 1928, a bordo del Spirit of St. Louis, completó un viaje de 15.100 kilómetros, conocido como "Good Will Tour". Entre el 13 de diciembre de 1927 y el 8 de febrero de 1928, recorrió distintos países de América Latina y el Caribe. En Ciudad de México, como era típico con los "ases del aire" en la fase "heroica", Lindbergh fue recibido por una multitud. Se calcula entre 100.000 y 200.000 las personas que se agolparon en el aeropuerto y por horas aguardaron expectantes la llegada del famoso aviador, que había perdido el rumbo correcto a causa de la oscuridad de la noche y la neblina. Estaba presente el 
presidente Plutarco Elías Calles y su comitiva; en México conoció además a su futura esposa, la hija menor del embajador estadounidense, Dwight Morrow.

Lindbergh visitó después las capitales de Guatemala, El Salvador, Nicaragua, Costa Rica, Panamá, Colombia, Venezuela, Puerto Rico, Cuba, entre otras capitales de países de la región, donde asimismo fue ovacionado por un público multitudinario. El diario New York Times informó con detalles sobre la travesía aérea del piloto, sus discursos y recepciones. Quizás haya pasado desapercibido, debido a la dimensión legendaria del personaje, que el 4 de febrero de 1928, durante el "Good Will Tour" por América Latina, Lindbergh recién había cumplido 26 años.

La aviación era sin embargo un fenómeno internacional que iba mucho más allá de cualquier individuo o nación. Desde sus experimentos exitosos con las máquinas más pesadas que el aire a inicios del siglo XX, generó una resonancia que se materializó en la producción cultural. La literatura relacionada con elementos aéreos no se interesó por factores cruciales del vuelo -estabilidad, seguridad, velocidad. Despreocupada de la utilidad y la visión pragmática, convirtió el vuelo en una aventura estética. Libres los escritores del drama de la vida y la muerte, anclados en el espacio doméstico o laboral, siempre protegidos por paredes y techos, la literatura "aérea" se propagó a un ritmo acelerado, solo comparable a la velocidad de las transformaciones de la propia aviación. La literatura se apoderó de las proezas y las tragedias, pero sobre todo del ansia humana por volar.

Ingold (1980) examinó la literatura europea de la aviación entre 1909 y 1927 y encontró una abundantísima producción en Francia, Alemania, Italia, Rusia, Inglaterra, Austria, Hungría. Y no de autores poco conocidos: Kafka, Marinetti, D’Annunzio, Rilke, Musil, Proust, Wells, von Hofmannsthal, Chlebnikov, Jünger, Zweig, entre otros. Después del automóvil, el aeroplano devino la nueva musa mecánica del futurismo. En su "Teoria e invenzione futurista" (11/5/1912), F. T. Marinetti partió de la metáfora aérea para cuestionar el valor del pasado: "In aeroplano, seduto sul cilindro della benzina, scaldato il ventre dalla testa dell'aviatore, io sentii l'inanità ridicola della vecchia sintassi ereditata da Omero" (Marinetti, 1968, p. 40) ("En el avión, sentado sobre el tanque de gasolina, con el vientre calentado por la cabeza del aviador, yo sentí la inanidad ridícula de la vieja sintaxis heredada de Homero").

Por la misma época, en Moscú, en el "Manifiesto del rayonismo" de 1913, Mijail Lariónov afirmó que "el genio de nuestra época debe ser: pantalones, chaquetas, zapatos, tranvías, autobuses, aeroplanos, barcos maravillosos" (citado en De Micheli, 1995, p. 383). El avión es lo nuevo, y como tal ingresó con fuerza en el léxico de las vanguardias.

Escritores de América Latina, de distintas nacionalidades y tendencias, pronto se sumaron a la narrativa del carro alado. Uno de los primeros textos teatrales del venezolano Rómulo Gallegos se titula "El motor" (1910) y tematiza el ansia de volar. El dato es interesante porque Gallegos, novelista, cuentista, ensayista, maestro y político (fue presidente de la República en 1947), autor de Doña Bárbara (1929), forma parte del grupo que integran los denominados "novelistas de la tierra", cuyos personajes luchan de manera pertinaz con el medio físico. El poeta brasileño Augusto dos Anjos murió en 1914, no sin antes dedicar un poema "A aeronave", en el cual "Sulcando o espaço, devassando a terra, / A aeronave que um mistério encerra / Vai pelo espaço acompanhando o mundo" (1998, p. 105). Vale la pena mencionar que Augusto dos Anjos había nacido en un ingenio de azúcar en el interior de Paraíba, en 1884, y que en vida solo publicó una obra, Eu (1912), compuesta por 58 poemas, en su mayoría sonetos.

Fueron los escritores vanguardistas quienes más aprovecharon los motivos aéreos en la producción cultural. A inicios de la década de 1920, se consideró al brasileño Agenor Barbosa un "futurista" por su poema "Os pássaros de aço", aunque casi nada tiene Barbosa del electrizante y renovador léxico futurista, fuera del tema de la aviación (Bosi, 1994, p. 338). Diferente es el caso del chileno Joaquín Edwards Bello, que, inspirado por la idea del absurdo proclamada por el dadaísmo, publicó con el seudónimo Jacques Edwards el poema "Aviación" (Metamorfosis, 1921). Por su parte, el peruano Alberto Hidalgo, en "Visión simplista desde 2000m. de altura” (Simplismo, 1925) escribe: 




La poética de Hidalgo pasa del modernismo a la vanguardia, en su versión futurista, cuando el poeta reside en la fervorosa Buenos Aires y funda su propia escuela, el Simplismo, que entiende la poesía como el arte personal de pensar en metáforas subjetivas.

También en la década de 1920, el guatemalteco Miguel Ángel Asturias, que alega que nunca había podido andar en bicicleta, decidió aprender a pilotar un aeroplano en Francia, en una de sus numerosas escuelas. Luego de la primera lección, más seguro de sí mismo, al volver a su casa comentó: "me sentí otro, menos mueble, menos animal doméstico, menos vegetal con raíces. Traía alas" (Asturias, 1997, p. 302). Asturias se mueve de este modo en el amplio espectro de lo moderno; después de estudiar economía política en Londres, en París desarrolla el conocimiento de la literatura maya y traduce del francés al español el Popol Vuh, el libro sagrado de los quiché-mayas. Ello confirma que el uso de la mitología americana, que incorporó en su novelística y le valió el Premio Nobel de Literatura en 1967, no entra en contradicción con los movimientos de vanguardia que realzan las técnicas modernas.

En México, el escritor y diplomático Luis Quintanilla, miembro por corto tiempo del Movimiento Estridentista, edita Avión (1923), con una carátula del Dr. Atl, que representa una hélice. A Quintanilla lo anima la metáfora del pájaro que rompió su jaula y se echó a volar: la estética vanguardista abandona la visión terrestre para manifestar la cambiante relación entre el suelo y el cuerpo humano, como en el siguiente fragmento del poema "Avión”: “iADIÓS TIERRA! / A la que tanto me gustó cantar / Ahora / Mi corazón de acero / Vibra mecánicamente / ¡ADIÓS TIERRA A LA QUE TANTO ME GUSTÓ CANTAR!” (pp. 117-118).

Los estridentistas mexicanos fueron mensajeros entusiastas de la emoción de la vida moderna como motor de la creación estética. Las máquinas surgen por doquier, especialmente en la imaginación y la voluntad de escándalo. Además de los automóviles, tranvías, motocicletas, dínamos y cables, están los aviones: "y ante la gloriosa cruz de un aeroplano, los pegasos tienen que descender vergonzantes a los pesebres burocráticos” (Manifiesto Estridentista Número 3, citado en Schwartz, 1991, p. 172). Es la época, en la ingeniosa formulación de List Arzubide, de los "paisajes aviónicos”. Un ejemplo al respecto es el poema de Manuel Maples Arce, "Canción desde un aeroplano" (Poemas interdictos), consagrado como uno de los más perfectos de la poesía mexicana y uno de los más relevantes de la vanguardia en castellano (Schneider, 1985, p. 31).

Chile es conocido como el país de los poetas. En 1929, el médico cirujano Juan Marín publicó el poemario Looping, cuya carátula es una hélice. Podemos olvidar sin remordimientos este poemario, así como su novela Margarita, el aviador y el médico (1932). Muy distinto es el caso de Vicente Huidobro, que experimenta con la imagen del aeroplano en Hallali y Ecuatorial. En Altazor o el viaje en paracaídas, ese notable poema en siete cantos, publicado en Madrid en 1931 con un retrato del autor realizado por Picasso, el verdadero protagonista es el lenguaje, que rompe con la estética tradicional desde la perspectiva aérea y la metáfora aeronáutica.

En la producción cultural latinoamericana se manifestaron las contradicciones contenidas en las exigencias modernizadoras, en particular de la aeronavegación. Vida vertiginosa es el título del libro que el cronista, periodista, cuentista y dramaturgo João do Rio publicó en Rio de Janeiro en 1911. João do Rio (1881-1921), miembro de la Academia Brasileña de Letras, que no ocultaba su inclinación homoerótica, fue un observador 
sensible de la época contemporánea, de las transformaciones de los usos, costumbres e ideas. De hecho, en el epígrafe señala que Vida vertiginosa, tal vez más que sus otros libros, tiene la preocupación del momento.

Sintomáticamente, el cronista carece de la experiencia directa de la vida vertiginosa. Un cuento como "A era do automóvel", el primero de Vida vertiginosa, refleja más la agudeza de la observación que la vivencia personal. En ese sentido, expresa fielmente las contradicciones del futurismo periférico, que narra las transformaciones desde la perspectiva del observador externo. "O dia de um homem em 1920" es el cuento final del libro y de nuevo manifiesta las ambivalencias frente a la modernización. El personaje del "hombre superior" es un histérico absoluto, una caricatura del empresario up-to-date. Duerme poco y mal, lo despierta un despertador eléctrico último modelo, aprieta botones, hace gimnasia sueca mirando el reloj. Almuerza píldoras concentradas de alimentos poderosos. Recibe telegramas y se desplaza en avión, sube y baja ascensores a gran velocidad, explota sin piedad a los empleados. A los treinta años está calvo y con una dentadura postiza. Este hombre-superior siempre tiene prisa: solo está interesado en la velocidad y en el lucro. No tiene tiempo para perder con frivolidades, incluso olvida el entierro de su hija.

Una perspectiva opuesta se encuentra en el poema del joven Jorge Luis Borges, "Catedral". Poema publicado en la revista Baleares en 1921, el símbolo religioso de la catedral funciona como una representación de la tradición, pero aparece asociado a la figura del avión. Escribe Borges que "La catedral es un avión de piedra / que puja por romper las mil amarras / que la encarcelan / la catedral sonora como un aplauso / o como un beso" (Borges, 1921). La imagen de la catedral como un avión de piedra remite a la conjunción de tradición y modernidad que constituye un elemento central de la literatura latinoamericana. Sin duda podemos entender la catedral como un paradigma arquitectónico del deseo de la elevación, así como encontramos en las distintas poéticas estudiadas por Ingold (1980, p. 337-369) ejemplos de la aspiración a la elevación angelical y artificial (Bolte, 2015, p. 31).

Entre ambos extremos -la vida del futuro en los rascacielos y la arquitectura del pasado registrada en clave moderna- se despliegan distintas vertientes que tematizan la movilidad aérea. La crónica de Cecília Meireles, "Uma aventura formidável"; la novela de Pedro Prado, Alsino; los poemas de Emilio Frugoni en La epopeya de la ciudad; los ensayos de José Vasconcelos, La raza cósmica y de Renato Almeida, Velocidade, todos comparten alguna referencia a la figura del aeroplano.

El léxico de la aviación se ramifica en los ámbitos más inesperados; por ejemplo, el mestizaje. En La raza cósmica: misión de la raza iberoamericana. Notas de un viaje a la América del Sur, libro que se publica en 1925 en Barcelona, el abogado, educador, candidato a la presidencia y ensayista mexicano José Vasconcelos presenta la tesis de que "las distintas razas del mundo tienden a mezclarse cada vez más, hasta formar un nuevo tipo humano, compuesto con la selección de cada uno de los pueblos existentes" (1948, p. 9). ¿Cuál es la relación entre el mestizaje, entendido como la cuna de la humanidad nueva, y la aviación? Ninguna de las fuentes que inspiraron a Vasconcelos -la Nueva Geografía Universal de Elisée Reclus, Les races et l'historie de Eugène Pittard, Ideas para una concepción biológica del mundo de Jakob von Uexküll- apuntan a la vinculación entre mestizaje y aviación. En cambio, en La raza cósmica, la tierra de promisión es el trópico, esa zona cálida de América que albergará la formación de una quinta raza universal. Si el destino futuro del mundo depende de la conquista de la región amazónica, ello se debe a los avances de la ciencia y del maquinismo, y a la evolución de los medios de transporte y comunicación. Por supuesto, dada la orientación "arielista" (cristiana) de Vasconcelos, la dimensión material ocupa un rol secundario. En todo caso, "cerca del gran río se levantará Universópolis y de allí saldrán las predicaciones, las escuadras y los aviones de propaganda de buenas nuevas"; "si la quinta raza se adueña del eje del mundo futuro, entonces aviones y ejércitos irán por todo el planeta, educando a la gente para su ingreso a la sabiduría” (Vasconcelos, 1948, p. 35). 


\title{
DESDE El VIAJE POR EL PARAÍSO PERDido A LA VUlgaridAd DE LOS AVIONES: Borges Y SAER (PASANDo POR EL QuiJote DEL AIRE)
}

Varios escritores latinoamericanos reflejaron el pasaje de la fase heroica a la impersonalidad del vuelo. En "El viaje en globo", Jorge Luis Borges anota:

\begin{abstract}
Como lo demuestran los sueños, como lo demuestran los ángeles, volar es una de las ansiedades elementales del hombre. La levitación no me ha sido aún deparada y no hay razón alguna para suponer que la conoceré antes de morir. Ciertamente el avión no nos ofrece nada que se parezca al vuelo. El hecho de sentirse encerrado en un ordenado recinto de cristal y de hierro no se asemeja al vuelo de los pájaros ni al vuelo de los ángeles. Los vaticinios terroríficos del personal de a bordo, con su ominosa enumeración de máscaras de oxígeno, de cinturones de seguridad, de puertas laterales de salida y de imposibles acrobacias aéreas no son, ni pueden ser, auspiciosas. Las nubes tapan y escamotean los continentes y los mares. Los trayectos lindan con el tedio. El globo, en cambio, nos depara la convicción del vuelo, la agitación del viento amistoso, la cercanía de los pájaros (1991, p. 416).
\end{abstract}

El viaje en globo de Borges tuvo lugar en el valle de Napa, California. Fueron cinco pasajeros y el piloto los que participaron del paseo en aquella fresca madrugada californiana, mientras clareaba el día y se abrían los viñedos y los campos. La contraposición entre el vuelo en globo y el avión, típicamente romántica, entronca con el sentimiento de felicidad: el vuelo produce felicidad en el espacio abierto. Podemos imaginar a Borges, ciego, apoyadas las manos en la borda de la barquilla, sintiéndose feliz en el espacio despejado, el viento del alba acariciando su frente, nuca y mejillas. Pero este periplo aéreo, que duró una hora y media, es asimismo un recuerdo de los grabados de globos de las enciclopedias de su infancia y un viaje literario e histórico. Escribe Borges que el paseo "era también un viaje por aquel paraíso perdido que constituye el siglo XIX. Viajar en el globo imaginado por Montgolfier era también volver a las páginas de Poe, de Julio Verne y de Wells” (p. 417).

En este ámbito literario, cuando pensamos en los pioneros de la aviación con la máquina más pesada que el aire, podemos rememorar la figura de Don Quijote. De hecho, observadores en la década de 1920 compararon al aviador con el domador idealista que enfrentaba condiciones adversas, un mártir del progreso humano y tecnológico. Así sucedió con el viaje de Ramón Franco en el hidroavión Plus Ultra en 1926 de España al Río de la Plata, en el cual el comandante español fue concebido como el héroe latino en su pájaro mecánico, un Quijote del aire, enhebrador de estrellas que domaba los vientos, vencía el destino y le suprimía al idioma castellano la palabra "imposible". Tales perspectivas idealizadas del temprano aviador, que ocultan los aspectos nacionalistas, colonialistas, políticos y bélicos de la aviación, remiten a una contraposición más profunda e insidiosa entre el individuo y el sistema, entre la libertad individual y la mecanización.

Por su parte, Juan José Saer, en El río sin orillas, declaró que el espanto y la vulgaridad eran el patrimonio principal de los aviones. Arremetió contra la cultura del ocio y del falso entorno agradable creado por los profesionales de lo aéreo. Y, sin embargo, como contradiciendo en parte lo afirmado, reconoció que una mañana de primavera, en el avión semivacío en el cual estaba llegando a Buenos Aires, "hubo un momento mágico". Fue cuando, desde la cabina de comando, el piloto informó que podían contemplar "el punto en que confluyen el río Paraná y el río Uruguay para formar el Río de la Plata”. Fue especial para Saer, que vivía en Francia, porque

ese lugar chato y abandonado era para mí, mientras lo contemplaba, más mágico que Babilonia, más hirviente de hechos significativos que Roma o que Atenas, más colorido que Viena o Ámsterdam, más ensangrentado que Tebas o Jericó. Era mi lugar: en él, muerte y delicia me eran inevitablemente propias (Saer, 2003, p. 15).

Quizás los aeropuertos pasaron a semejarse a estaciones de autobús y a lugares de tránsito, al punto que fueron incluidos en la lista de "no lugares" por Marc Augé. No obstante, el avión todavía propicia, como nos recuerda Saer pese a su denuncia de la vulgaridad de la aviación, momentos emocionantes, especialmente antes del aterrizaje en los lugares queridos. 


\section{Conclusión: EL ALCANCE PLANETARIO DE LA AEROMOVILIDAD}

Tan solo poco más de cien años después de su despegue oficial en 1906, la aeronavegación devino en un modo de vida que incide directa e indirectamente en las prácticas, experiencias y afectos de los sujetos. Si hoy aceptamos el término "aeromovilidad", acuñado a comienzos del tercer milenio en el marco del "giro de la movilidad" (mobility turn), que piensa "de forma holística al movimiento como un entramado de los movimientos físicos de personas, bienes e información”, es porque expresa el alcance planetario de la aviación y de sus efectos combinados en el ámbito político, económico, tecnológico, social y cultural (Piglia, 2017, p. 33).

Dado el marco de las interacciones planetarias, ¿qué se puede decir sobre la aeromovilidad a inicios del tercer milenio? El Covid-19, que restringió severamente, aunque de modo temporario, el número de desplazamientos aéreos, asestó un duro golpe a las compañías aéreas y al turismo global. Desde el punto de vista del control del virus, implicó en gran medida el pasaje del puerto al aeropuerto. La primera epidemia documentada de la historia, la peste de Atenas que asoló la ciudad-estado en el año 430 a.C. y diezmó a la población, se originó probablemente en Etiopía y descendió a través de Egipto y Libia hasta su llegada por el puerto del Pireo a Atenas. Algo semejante se puede afirmar de la Peste Bubónica, del siglo XIV, la más devastadora pandemia de peste en la historia de la humanidad, que afectó de manera central a Eurasia. Sorprende el trayecto desigual de la peste: su origen fue seguramente un brote causado por la variante de una bacteria en Asia y desde allí se transmitió a Europa a través de rutas comerciales. Mientras algunas áreas del Viejo Mundo quedaron básicamente despobladas, otras fueron muy poco afectadas. Una de las ventajas del mundo aún no por completo globalizado fue que contuvo el alcance territorial de la enfermedad a Eurasia. Un siglo y medio después, en el siglo XVI, las víctimas fueron los indígenas americanos, que no poseían inmunidad contra las enfermedades transmitidas por los europeos. En los ejemplos mencionados, los puertos fueron el lugar privilegiado de la entrada del virus. En la actualidad, esa dudosa honra le corresponde a los aeropuertos.

Por tal razón, debemos extender la imagen plástica de los navegantes obligados a rehacer el barco en altamar. Aunque el naufragio con espectadores (metáfora investigada por Hans Blumenberg) continúa siendo la imagen privilegiada, desde el despegue de la modernidad cinética el motivo aéreo coloniza crecientemente el territorio de la imaginación. Como lo advirtió el filósofo alemán Peter Sloterdijk, que hace referencia al trabajo de Blumenberg, con la apertura del espacio aéreo la imagen mental náutica compite con el motivo icario. Y en tono sombrío añade el filósofo de Karlsruhe:

Y parece que todavía a nadie se le ha ocurrido la idea de que hubiera que rehacer los aviones durante el vuelo a gran altura. Aunque de vez en cuando se escucha, sin embargo, el temor de que el avión, a bordo del cual la humanidad viaja a su futuro, haya salido antes de que los técnicos instalaran el tren de aterrizaje (Sloterdijk, 2015, p. 54).

Más allá del diagnóstico filosófico, optimista o sombrío, del futuro de la civilización apoyado en la metáfora aérea, el concepto de aeromovilidad implica pensar el avión como fragmento de un colosal entramado social en el cual el despliegue de la técnica icaria genera beneficios pero también riesgos, contaminaciones y efectos colaterales paradójicos a nivel planetario.

\section{REFERENCIAS}

Anjos, A. dos. (1998). Eu e outras poesias. Rio de Janeiro: Civilização Brasileira. Asturias, M. Á. (1997). Periodismo y creación literaria (París 1924-33). Paris: Archives.

Barthes, R. (1999). El hombre-jet. En Mitologías (pp. 52-54). México: Siglo XXI. 
Bolte, R. (2015). Azorando la percepción: la escritura del vuelo en Altazor - Voyage en parachute / Viaje en Paracaidas (1919-1931) de Vicente Huidobro. En S. Schlünder (Coord.), Literatura y técnica: derivas materiales y ficcionales (pp. 21-47). La Plata: Ediciones Del lado de acá.

Borges, J. L. (1921). Catedral. Baleares, V, (131).

Borges, J. L. (1991). El viaje en globo. En Obras completas, Vol. 3 (pp. 416-417). Buenos Aires: Emecé.

Bonilla, J. (2010). Ultraísmo en Ultramar. Cuadernos Hispanoamericanos, 720, 95-114.

Bosi, A. (1994). História concisa da literatura brasileira. São Paulo: Cultrix.

Chanute, O. (1894). Progress in Flying Machines. New York: Dover Publications.

Crouch, T. (1989). The Bishop's Boys. A Life of Wilbur and Orville Wright. New York: W. W. Norton.

De Micheli, M. (1995). Las vanguardias artísticas del siglo XX. Madrid: Alianza Forma.

Douhet, G. (1987). El dominio del aire. Madrid: Instituto de Historia y Cultura Aeronáutica.

Earhart, A. (1988). Last Flight. New York: Orion Books

Edwards Bello, J. (1979). Metamorfosis. Santiago de Chile: Nascimento.

Eksteins, M. (1990). Rites of Spring. The Great War and the Birth of the Modern Age. Boston: Houghton Mifflin.

Ford, H. (1926). Today and Tomorrow. London: William Heinemann.

Freud, S. (1989). La interpretación de los sueños. En Obras completas, Vol. IV. Buenos Aires: Amorrortu.

Gallegos, R. (1959). El motor. Madrid: Edime.

Hidalgo, A. (1925). Simplismo: poemas inventados. Buenos Aires: El Inca.

Ingold, F. P. (1980). Literatur und Aviatik. Europäische Flugdichtung 1909 bis 1927. Frankfurt a. M.: Suhrkamp.

Lindbergh, C. (1927). We. New York: G. P. Putnam's Sons.

Lindbergh, C. (1953). The Spirit of St. Louis. New York: Charles Scribner's Sons.

Lindbergh, C. (1992). Autobiography of Values. New York: Harcourt Brace Jovanovich.

Lovell, M. S. (1989). The Sound of Wings. The Life of Amelia Earhart. New York: St. Martin's Press.

Marinetti, F. T. (1968). Teoria e invenzione futurista. Milano: Mondadori.

Marinetti, F. T. (2012). Manifiestos y textos futuristas. Madrid: Terramar.

Piglia, M. (2017). Aeromovilidad. En Z. S. Dhan, G. Giucci y P. Jirón (Eds.), Términos clave para los estudios de movilidad en América Latina (pp. 532-543). Buenos Aires: Biblos.

Quintanilla, L. (1923). Avión. México: Editorial Cultura.

Rio, J. do. (1911). Vida vertiginosa. Rio de Janeiro: Garnier.

Saer, J. J. (2003). El río sin orillas. Tratado imaginario. Buenos Aires: Seix Barral.

Schneider, L. M. (1985). El Estridentismo. México, 1921-1927. México: Universidad Autónoma de México.

Schwartz, J. (1991). Las vanguardias latinoamericanas. Textos programáticos y críticos. Madrid: Cátedra.

Scott Berg, A. (1998). Lindbergh. New York: G. P. Putnam's Sons.

Sloterdijk, P. (2015). Los hijos terribles de la edad moderna. Sobre el experimento antigenealógico de la modernidad. Madrid: Siruela.

Vasconcelos, J. (1948). La raza cósmica: misión de la raza iberoamericana. Notas de un viaje a la América del Sur. México: Espasa-Calpe.

Wohl, R. (1994). A Passion for Wings. Aviation and the Western Imagination, 1908-1918. New Haven: Yale University Press.

Wohl, R. (2005). The Spectacle of Flight. Aviation and the Western Imagination, 1920-1950. New Haven: Yale University Press. 